\title{
Targeting international consumers in the long-distance telephone services market
}

\author{
RECEIVED (IN REVISED FORM): 24 AUGUST, 2000 \\ Tao Qin, Thomas W. Whipple* and Rajshekhar G. Javalgi \\ *College of Business Administration, Cleveland State University, 1983 East 24th St., \\ Cleveland, $\mathrm{OH} 44 \mathrm{II5}$, USA. \\ e-mail: t.whipple@popmail.csuohio.edu
}

\begin{abstract}
A segment of heavy users in the international long-distance telephone services market was studied to understand the importance of carrier selection criteria. International students attending a US university rate relative price, reliability of lines and complaint handling as the three most important factors when selecting a long-distance carrier. The relative importance of criteria varies, however, by past switching behaviour and by current carrier. Switchers, unlike non-switchers and ATET customers, rate switching incentives and economic rate scheduling as more important than reliability of lines and complaint handling in the carrier selection process. The profiles of switchers and non-switchers are significantly different as well. Implications for appropriate customer attraction and retention strategies to be used by longdistance carriers targeting these switching behaviour segments are discussed with respect to relationship, database, and Internet marketing tactics.
\end{abstract}

\section{INTRODUCTION}

Ongoing global technological advancements in the telecommunication service industry have forged a network of global linkages that connect us all: countries, institutions and individuals. Now we can live far apart, yet feel closer to each other. Telecommunication companies provide new international bridges that connect voices instantaneously. To reach consumers around the globe, long-distance telephone, local telephone and cable companies are employing aggressive and innovative tactics to provide long-distance telephone services more efficiently. $^{1}$

The international long-distance telephone business is growing at an unprecedented rate. With the deregulation of the telecommunications industry, competition in the long-distance telephone market has become more intense. Competitive threats arise from both inside and outside the industry. ${ }^{2-5}$ Competition includes callback services that allow customers to make international calls through a third country, such as the USA, and to save as much as 50 per cent on overseas calls. ${ }^{6,7}$ Long-distance telephone service is a huge market. AT\&T, MCI WorldCom and Sprint
Tao Qin is an international marketing specialist at Timken, Inc. in Akron, Ohio and a doctoral candidate for a DBA in business administration at Cleveland State University, Ohio.

Thomas W.

Whipple Phd, is Professor of Marketing in the College of Business

Administration, Cleveland State University, Ohio.

Rajshekhar G. Javalgi $\mathrm{PhD}$, is Professor of Marketing in the College of Business Administration, Cleveland State University, Ohio. 
control almost 90 per cent of the more than $\$ 100 \mathrm{bn}$ US long-distance business. ${ }^{8,9}$

Because of technological innovations in the telecommunication industry and the entrance of new competitors, the industry is becoming more market driven. To face challenges involving risks and opportunities, long-distance telephone providers are using marketing concepts to differentiate themselves from competitors. ${ }^{10}$ To devise new strategies they are employing sophisticated research tools to discern consumers' selection processes with regard to long-distance telephone service providers.

Selection of a carrier is crucial for those consumers who make international telephone calls on a regular basis. Understanding consumers' behaviour in selecting a service provider will help long-distance telephone companies improve customer loyalty, increase market share and maintain a competitive advantage. Few studies have focused on the long-distance carrier selection process. ${ }^{11,12}$ This study fills this gap by focusing on how a specific frequent international caller segment, the international student market, chooses a long-distance carrier.

Understanding the long-distance carrier selection process of this group is critical for long-distance telephone companies for several reasons. According to the US Department of Education, the number of foreign students enrolled in institutions of higher education in the USA increased from 311,000 to 450,000 in 15 years and this trend is expected to continue. ${ }^{13}$ International students make international calls regularly. They call their families and friends back home. Most of them spend two to three times more per month on long-distance calls, compared to the average of $\$ 40$ for a typical American family. ${ }^{14}$ Because of their limited incomes and the need to make regular international telephone calls, these students are sensitive to price changes and promotions for specific international calling plans. A significant portion of students in this group switch long-distance carriers from time to time, whereas 85 per cent of American households stay with their current providers. ${ }^{15}$

The international student group is a growing segment in the long-distance calling market and its importance should not be overlooked. Customers in this segment are heavy users of long-distance telephone services. First, this segment represents huge revenues. With an average long-distance bill that exceeds $\$ 100$ a month, an annual revenue of $\$ 600 \mathrm{~m}$ is expected. Secondly, the customer loyalty in this segment is low and switching of service carriers is frequent. Understanding the selection process of this segment will help long-distance telephone companies develop better strategies to build customer loyalty and to maintain competitive advantage. ${ }^{16}$ Thirdly, marketing strategies designed for this segment may have long-term effects as a significant percentage of people in this group will probably stay in the USA after finishing university. 
Considering this factor, the long-term revenue generated by this segment could be enormous. In addition, those students who return to their home countries may play a positive role in the global expansion of US longdistance telephone companies.

\section{EXISTING RESEARCH}

Flanagan found that reliability of telephone lines is highest in importance in the selection of a long-distance carrier and that the cheapest calling rate is only fifth in importance ${ }^{17}$ Egolf, on the other hand, noted that relative price is a critical factor when choosing a telephone service provider. ${ }^{18}$

Service quality has emerged as a major tool for differentiation of services as technology becomes standardised. ${ }^{19}$ Sephton found that simplicity of service and billing procedures is an important consideration in the selection of a carrier. ${ }^{20}$ In addition, personnel-related factors, such as those relating to complaint handling/error correction and the attitude of operators, are important considerations. ${ }^{21}$ An unpleasant experience with an operator or a salesperson seeking new customers may make prospective customers reluctant to switch carriers even if they are offered very good deals. Briere suggested that to serve new immigrant/ethnic segments, telephone companies should offer them native language support and loyalty reward programmes. ${ }^{22}$ The company reputation of the major brands of long-distance service still plays an important role in the selection of carriers. ${ }^{23}$ Snyder found that most customers prefer to do business with a company they know and suggested customers take advantage of special switching incentives. ${ }^{24}$ Finally, Hills found that economic rate scheduling influences service provider choices. ${ }^{25}$

From the literature, at least three observations can be made. First, research has not focused on identifying features that are important to customers of different long-distance service providers. Secondly, research emphasising the switching behaviour of consumers is sparse. Finally, little consideration has been given to the ramifications of the possibility that those consumers who stay (nonswitchers) with the same long-distance service provider may differ from those who switch to other long-distance carriers. This paper focuses on these important research questions.

\section{RESEARCH OBJECTIVES}

Unequivocally, in terms of market size and potential, the international student segment is growing and offers profit potential for service providers in the long-distance telephone market. The realisation that this student market should not be ignored provides new opportunities for long-distance telephone companies such as AT\&T, MCI WorldCom and Sprint. In this highly competitive industry, consumers are offered a greater number of choices than ever before. Those companies that 
analyse preferences and behaviours of potential customers, and develop sound marketing programmes tailored to meet their needs, can expect to survive and to be successful. Four specific objectives of this study are to:

- determine the degree of importance of factors international students use in selecting a long-distance service provider

- identify the criteria that vary in importance among customers of major long-distance service providers

- identify the criteria that are significant in differentiating between switching and non-switching groups

- develop profiles of switching and non-switching customers of AT\&T, MCI WorldCom and Sprint.

\section{RESEARCH METHODOLOGY}

Research methodology consisted of three phases. The first phase involved the development of a questionnaire to determine what international students want from long-distance telephone companies. To accomplish this task, exploratory research (eg ten in-depth interviews) was conducted with international students who came from different cultures with a variety of economic standings and backgrounds. Based on their input and a literature review, ${ }^{26-32}$ a questionnaire was developed and pre-tested. In the survey, each respondent was asked to indicate the relative importance of ten criteria (Table 1) used in selecting a longdistance carrier. An unbalanced scale ranging from one (unimportant) to five (essential) was used. Respondents were asked to provide information on the average amount of monthly international call spending, the name and length of service of their current long-distance provider, telephone usage behaviour, relative preference of providers and the likelihood of switching to another service provider. In addition, respondents were asked to provide information on a variety of demographic variables.

In the second phase of the research design, the sample selection process was determined. To represent international students attending urban universities, a midwest metropolitan state university was selected. The questionnaires were distributed to students using a non-probability sampling method. Researchers' judgment played an important role in the inclusion of students from different countries with a variety of demographic backgrounds. Responses were obtained from 222 students, representing over 30 per cent of the international population. Fifteen respondents were eliminated, due to incomplete data, resulting in an analysis sample of 207 students. The analysis, described below, completed the research methodology.

\section{ANALYSIS AND FINDINGS}

\section{Characteristics of the respondents}

The 207 respondents include $150(72$ per cent) graduate students and 131 (63 per cent) males. They ranged in age 
from 18- to 45-years old. With respect to country of origin, the four largest international student groups came from: China (26 per cent), Thailand (23 per cent), Indonesia (11 per cent), and India (7 per cent). The remaining 33 per cent came from more than 30 other countries. One hundred and forty-three (69 per cent) are full-time students, 53 (37 per cent) of which have a part-time job. The remaining respondents (31 per cent) have full-time jobs and are part-time students.

International students use long-distance telephone services primarily for calling their families and/or friends in their home countries (89 per cent). Almost 10 per cent of their monthly living expenses $(\$ 1,800)$ are spent on long-distance calls $(\$ 170)$. More than 82 per cent of their calls are international. On average, international students make 11 international calls a month and each call averages at least 15 minutes. Consequently, international student customers are heavy users of long-distance telephone services and are an important revenue source for the long-distance carriers.

Among the 207 respondents, 114 (56 per cent) are AT\&T's customers, 61 (30 per cent) chose MCI WorldCom as their service provider, 22 (11 per cent) are Sprint customers, and eight (4 per cent) chose another service provider (eg LCI). Respondents stay with their service provider for 9.7 months, on average.

Among those who did switch their long-distance service provider last year,
69 (60 per cent) switched because they were called by competitive service providers, 16 (14 per cent) knew of offers by word-of-mouth, and 15 (13 per cent) students called the companies to inquire about switching. Advertising was perceived by respondents to play a very limited role in the switching decision (7 per cent).

When asked about how long they will stay with a company once they make a switch, 39 (34 per cent) said they will stay for the whole promotion period and 26 (23 per cent) intended to stay longer. Twenty-nine (25 per cent) are incentive shoppers and will switch again once they receive the incentives (free minutes or free cheques). Twenty-one (18 per cent) feel some moral responsibility and will stay for a few months.

\section{Criteria deemed important in selecting a long-distance carrier}

The average importance ratings of the ten carrier selection criteria are presented in Table 1. The most important criterion in selecting a long-distance company is relative price (4.08). Four criteria follow price as significantly less important: reliability of lines (3.65), complaint-handling (3.60), economic rate scheduling (3.56) and switching incentives (3.54). In addition, the findings reveal that the attitude of operators (3.30) is significantly more important than the remaining four factors. These students appreciate an international operator with a gentle and friendly tone when they are calling to converse with 
Table 1

AVERAGE IMPORTANCE OF SELECTION CRITERIA BY CARRIER

\begin{tabular}{|c|c|c|c|c|}
\hline Selection criteria & Total & AT\&T & MCI WorldCom & Sprint \\
\hline Relative price & 4.08 & 4.10 & 4.10 & 4.27 \\
\hline Reliability of lines $\star$ & 3.65 & 3.83 & 3.33 & 3.50 \\
\hline Complaint handling & 3.60 & 3.59 & 3.55 & 3.73 \\
\hline Economic rate scheduling & 3.56 & 3.58 & 3.60 & 3.64 \\
\hline Switching incentives & 3.54 & 3.56 & 3.60 & 3.68 \\
\hline Attitude of operators & 3.30 & 3.45 & 3.05 & 3.32 \\
\hline Company reputation $\star$ & 3.08 & 3.31 & 2.78 & 2.68 \\
\hline Simplicity of procedures & 3.04 & 3.10 & 3.01 & 2.95 \\
\hline Gifts based on usage & 3.00 & 2.94 & 2.95 & 3.18 \\
\hline Native language support & 2.53 & 2.39 & 2.79 & 2.59 \\
\hline
\end{tabular}

* Significant difference among average importance ratings for three carriers at $\mathrm{p}<0.01$ on scale: 1 = Unimportant, $2=$ Neither important nor unimportant, $3=$ Important, $4=$ Very important, 5 = Essential.

friends and/or relatives on the other side of the world. Company reputation (3.08), simplicity of service procedures (3.04), gifts based on usage (3.0) and native language support (2.53) are less important selection criteria.

In Table 1, respondents were divided into three groups based upon their current carrier. AT\&T customers rate the selection criteria in the same order of importance as the total sample of respondents. MCI WorldCom and Sprint customers, however, do not. They rate two selection criteria, reliability of lines and company reputation, significantly lower in importance. These two criteria have formed the basis of AT\&T's claim that its customers should not switch carriers.

\section{Switching behaviour}

The respondents were grouped into switching and non-switching segments based upon their last year's switching behaviour pattern. Those who switched more than once to a different long-distance company were classified as switching customers $(\mathrm{n}=70)$. The remainder were classified as nonswitchers $(\mathrm{n}=126)$.

The average importance ratings of the ten carrier selection criteria for both the switching and non-switching segments are presented in Table 2. To facilitate a comparison between the two groups, each set of average scores was rank ordered to indicate their relative importance to each segment. 
Table 2

\section{RELATIVE IMPORTANCE OF CARRIER SELECTION CRITERIA BY SWITCHING BEHAVIOUR}

\begin{tabular}{llccc}
\hline Selection criteria & Switchers & Rank & Non-switchers & Rank \\
Relative price & 4.17 & 1 & 4.08 & 1 \\
Reliability of lines & 3.44 & 5 & 3.76 & 2 \\
Complaint handling & 3.64 & 4 & 3.56 & 3 \\
Economic rate scheduling & 3.66 & 3 & 3.53 & 4 \\
Switching incentives & 3.90 & 2 & 3.37 & 5 \\
Attitude of operators & 3.26 & 6 & 3.33 & 6 \\
Company reputation & 2.77 & 9 & 3.25 & 7 \\
Simplicity of procedures & 2.96 & 7 & 3.13 & 8 \\
Gifts based on usage & 2.94 & 8 & 3.02 & 9 \\
Native language support & 2.43 & 10 & 2.58 & 10 \\
\hline
\end{tabular}

* Significant discriminating variables between switchers and non-switchers at $\mathrm{p}<0.01$ on scale: $1=$ Unimportant, $2=$ Neither important nor unimportant, $3=$ Important, $4=$ Very important, $5=$ Essential. Correct classification of the holdout sample was 67 per cent, significant at $\mathrm{p}<0.01$.

The relative importance of the carrier selection criteria varies between the two segments. The rank order of the ten selection criteria by nonswitchers is the same as for AT\&T customers. The switching group, however, gave a higher importance ranking to switching incentives than did the non-switchers. The switchers ranked switching incentives as the second most important feature, whereas the non-switchers group ranked such incentives as only fifth in importance.

\section{Discriminating variables}

How does the switching segment differ from the non-switching segment? While the descriptive measures presented in Table 2 provide insightful information about the relative importance of the carrier selection criteria, further analysis was needed to provide a better understanding of which criteria discriminate between the switching and non-switching groups.

Discriminant analysis classified the students into two groups (Table 2). The three carrier selection criteria that discriminate between the two groups are switching incentives, company reputation and reliability of lines. These findings suggest that switchers 
Table 3

\section{PROFILE ANALYSIS OF SWITCHERS AND NON-SWITCHERS}

\begin{tabular}{|c|c|c|}
\hline Customer characteristics & Switchers & Non-switchers \\
\hline Average length of stay ${ }^{\star}$ & 4.4 months & 12.8 months \\
\hline Likelihood to switch^ & Positive & Negative \\
\hline Monthly living expense & $\$ 1,515$ & $\$ 2,028$ \\
\hline Age ${ }^{\star}$ & 30.0 & 25.7 \\
\hline AT\&T customer $\star$ & $31.6 \%$ & $68.4 \%$ \\
\hline MCI WorldCom customer & $45.9 \%$ & $54.1 \%$ \\
\hline Sprint customer & $45.5 \%$ & $54.5 \%$ \\
\hline
\end{tabular}

$\star$ Significant difference of student characteristics between switchers and non-switchers at $\mathrm{p}<0.01$.

consider switching incentives to be more important (3.90 vs. 3.37) in the carrier selection decision. Company reputation $(2.77$ vs. 3.25$)$ and reliability of lines (3.44 vs. 3.76) are less important to switchers than to non-switchers.

\section{Profile analysis: Switching segment vs. non-switching segment}

A profile analysis of switching and non-switching customers disclosed different characteristics between the two groups (Table 3). This analysis provides insightful information for decisionmakers in the long-distance telephone service industry.

The average length of stay with a long-distance service provider for the switching group was 4.4 months, whereas for the non-switching group it was more than one year. When asked about the intention of switching to another company in the future, the majority of switching customers indicated they would switch, while the non-switching group gave no indication of wanting to switch to another service provider. Non-switchers have strong positive perceptions of their service provider and tend to exhibit loyalty to the service provider.

Non-switching customers have better financial support than do their switching counterparts (monthly living spending of $\$ 2,028$ vs. $\$ 1,515)$. The switchers tends to be older (30.0 vs. 25.7 years old) and are more likely to switch to take advantage of free minutes or free cheques to save money.

An examination of Table 3 further reveals that among AT\&T customers, a higher percentage of customers are 
non-switchers (68.4 per cent vs. 31.6 per cent). MCI WorldCom and Sprint customers are similar with respect to switching behaviour. The 46 per cent who are switchers are more likely to be influenced by switching incentives and are not as concerned about reliability of lines and company reputation of their service provider.

\section{IMPLICATIONS AND CONCLUSIONS}

Analysis of the switching incentive policies used by the long-distance telephone companies revealed that they encourage switching and low customer loyalty. The policies, however, fail to retain valuable customers, such as heavy users, by focusing on relative price that is not a discriminant selection criterion and switching incentives that do not have positive long-term effects. The implication is that switching incentives are becoming a necessary part of an offer, similar to a low relative price, and are losing their appeal except as a way to lure new customers. Abuse of incentives encourages switching behaviours at a high cost that eventually hurts the industry and the profitability of longdistance carriers.

The international student market is a profitable market, but it is not a homogeneous segment. Because it consists of multiple segments that are measurable and substantial, one marketing strategy targeted at international students may not produce successful results. Instead, differentiated strategies are needed to appeal specifically to two different subsegments, the switchers and the non-switchers. Differentiation strategies not only enable marketers to devise sound marketing programmes, but they also aid in developing positioning themes. Furthermore, differentiation strategies are more critical and practical when consumers find it difficult to evaluate service offerings, as in the longdistance telephone services business.

In an attempt to sustain competitive advantage in the international student market, which is aggressively targeted by AT\&T, MCI WorldCom and Sprint have implemented successful shortterm acquisition strategies to gain customers from AT\&T. By focusing on relative price and switching incentives, however, it is easy for other carriers to copy them by matching their lower prices. MCI WorldCom and Sprint need to develop differentiated strategies that do not depend solely on value/price discrimination and that cannot be copied so quickly. One alternative is to focus on product differentiation, such as stressing reliability of lines in their marketing communications, to enhance their respective company reputations. Companies commonly share each other's lines and potential customers should be made aware that reliability is not the sole ownership of AT\&T.

After incurring the high cost of switching incentives to acquire international students as customers, customer retention strategies should be 
employed to keep them. Time-limited switching incentives can be offered to convert non-customers into customers, but loyalty programmes, such as gifts based on usage, should be readily available to convert the best customers into non-switching customers. This strategy will reduce the switching costs, such as high incentives and labour costs, incurred by the carriers. Other usage incentive programmes, such as offpeak calling plans, may appeal specifically to international students who want to keep down the costs of calling home. An incentive to talk longer at an off-peak time, given the time change to Asian countries, should encourage retention. A longitudinal research study needs to be conducted to gain a better understanding of the changing attitudes of this subsegment.

Increased service loyalty to MCI WorldCom and Sprint by their respective customers should be the long-term objective. Dick and Basu found that loyal consumers are less motivated to search for alternatives, are more resistant to counter-persuasion from other providers/brands, and are more likely to pass along positive word-of-mouth communication about the service to others. $^{33}$

For the non-switching segment, AT\&T should continue to act like a market leader and defend its position among international students. Since switching incentives are less important to both non-switchers and to AT\&T customers, AT\&T should not have to match the incentive offers to acquire new international students arriving at
US universities each year. Instead, a high-value positioning, excellent quality at an average price, based on a sound company reputation, can continue to be successful. Nonswitchers are more concerned about the reliability of lines that guarantees a clear line to Asia. If the call is not completed successfully, they want a reliable operator to resolve their problems promptly at all hours of the night. A customer retention strategy that enhances the carrier's image must offer relatively lower prices with usage to build the loyalty of the nonswitching group.

Database marketing techniques can be used to help long-distance telephone companies implement these strategies. After conducting an analysis of student calling patterns, customers should be rated based on their potential future profitability. Those deemed most profitable to retain by a carrier can be offered one-to-one incentives that appeal specifically to each student. The Internet can become a useful marketing tool to this specific segment, given their student status and access to the Internet at school.

Another implication of the results of this study is that the source of future switching customers is more likely to be from MCI WorldCom and Sprint. Currently, AT\&T has a stronger position in this competitive market. Because of AT\&T's reputation, nonswitching customers tended to choose AT\&T as their service provider. This favourable situation gives AT\&T an advantage in building customer loyalty 
and challenges MCI WorldCom and Sprint to develop their own effective marketing strategies to attract and retain non-switching customers.

The big three are going to face even more intense competition as local telephone and other telecommunications companies enter the longdistance market in a major way. Understanding customers' behaviour is a key to success. By finding market niches and positioning itself uniquely, a long-distance telephone company can maintain a sustained competitive advantage.

In conclusion, to meet challenges and to take advantage of opportunities in the long-distance telephone services market, service providers need to use innovative strategies to sustain their market share. Since the international student market continues to grow, the importance of this market cannot be ignored. This research should be conducted in other countries to determine if the importance of selection criteria changes. By integrating technological advancements in their long range planning, service providers should target, measure and analyse market segments to attract and retain customers and to build customer loyalty.

\section{REFERENCES}

1 Hirchman, C. (1997) 'A game of strategy', Telephony, Vol. 232, No. 4, pp. 68-70.

2 Snyder, A. (1995) 'Long distance: How to choose the company that's right for you', Money, Vol. 24, No. 7, July, pp. $106-115$.
3 Rockwell, M. (1996) 'IXCs long-term winners, study says', Communications Week, 8 January, p. 23.

4 Burns, G. (1994) 'The great international phone-call grab', Business Week, 14 March, p. 6.

5 Robson, P. (1994) 'Service suppliers of all shapes and sizes', Purchasing \& Supply Management, January, pp. 22-23.

6 Burns (1994) op cit.

7 Robson (1994) op cit.

8 Snyder (1995) op cit.

9 Montanye, J. A. (1997) 'Market power to do what? The case of AT\&T', Public Utilities Fortnightly, 15 July, pp. 22-25.

10 Finn, C. M. and Gascoyne, K. L (1995) 'What do customers want? Who cares?' Telephony, Vol. 228, No. 17, pp. 2432.

11 Kuritsky, A. P. et al. (1982) 'The development, testing, and execution of a new marketing strategy at AT\&T long lines', Interfaces, Vol. 12, No. 6, December, pp. 22-37.

12 Diehl, K. and Gillman, R. (1997) 'Why your customers switch?', Public Utilities Fortnightly, 15 April, pp. 37-40.

13 Digest of Education Statistics (1995) US Department of Education, Washington, DC.

14 Egolf, K. (1996) 'Voice of the people', Telephony, Vol. 230, No. 12, pp. 3850.

15 ibid.

16 Briere, D. D. (1994) 'Speaking in tongues', Telephony, Vol. 226, No. 7, pp. 30-33.

17 Flanagan, P. (1995) 'Study looks at long-distance carriers', Telecommunications (American Edition), Vol. 29, No. 9, September, p. 14. 
18 Egolf (1996) op cit.

19 Hills, T. (1994) 'How to move with the times?' Communications International, Vol. 21, No. 7, July, pp. 42-46.

20 Sephton, J. (1994) 'Network services: Choice without confusion', Telecommunications (International Edition), Vol. 28, No. 10, October, pp. 33-34.

21 Riggenbach, D. (1981) “"Listening” programs keep customers happy', Telephone Engineer \& Management, Vol. 85, No. 1, January, pp. 68-70.

22 Briere (1994) op cit.

23 Sellers, P. (1994) 'MCI WORLDCOM communications: Yes, brands can still work magic', Fortune, 7 February, pp. 133-134.
24 Snyder (1995) op cit.

25 Hills, M. T. (1989) 'Competition for credit card and international calls', Business Communications Review, Vol. 19, No. 1, January, pp. 48-52.

26 Egolf (1996) op cit.

27 Hills (1994) op cit.

28 Flanagan (1995) op cit.

29 Sellers (1994) op cit.

30 Snyder (1995) op cit.

31 Briere (1994) op cit.

32 Sephton (1994) op cit.

33 Dick, A. S. and Basu, K. (1994) 'Customer loyalty: Toward an integrated conceptual framework', Journal of the Academy of Marketing Science, Vol. 22, pp. 99-113. 